\title{
Seasonal Impact in the Frequency of Intrahepatic Cholestasis of Pregnancy
}

\author{
Cem Yaşar SANHAL ${ }^{1}$, Korkut DAĞLAR ${ }^{1}$, Özgür KARA ${ }^{1}$, Ayşe KIRBAŞ’', Dilek UYGUR ${ }^{1}$, Aykan YÜCEL ${ }^{1}$ \\ Ankara, Turkey
}

\begin{abstract}
OBJECTIVE: To evaluate the presence of any seasonal variation in the frequency of intrahepatic cholestasis of pregnancy (ICP).

STUDY DESIGN: A total of 126 cases with ICP were compared with a cohort of 37614 pregnant women who delivered. The diagnosis ICP was performed on the basis of severe itching and the absence of dermal rash and any other hepatic disease, with the co-existence of elevated serum aminotransferase levels and/or serum bile acid concentration. For each month and season, observed and expected ICP rates were analysed and compared by using chi-square statistics. Multivariate logistic regression was performed to investigate certain parameters on cumulative risk.
\end{abstract}

RESULTS: A significantly lower frequency of ICP in winter $(6 / 126(4.8 \%), p=0.001)$ and a significantly higher frequency in spring (44/126 (34.9\%), $p=0.034)$ were detected. A 2.1 and 3.8-fold higher risk were found for the nulliparity and the twin pregnancy, respectively. Logistic regression analysis confirmed the significant (10-fold) decrease in the frequency of ICP in winter. The significance of spring did not persist after the adjustment.

CONCLUSION: Main outcome of the study points at seasonality in ICP frequency. Future studies in different populations may reveal data about factors that interact with seasonality and playing roles in ICP.

Keywords: Intrahepatic cholestasis of pregnancy, Season, Frequency, Variation

Gynecol Obstet Reprod Med 2016;22:5-9

\section{Introduction}

Intrahepatic cholestasis of pregnancy (ICP), which occurs mostly in the second or third trimester of gestation in a previously healthy woman, is characterized by the co-existence of pruritis and elevated fasting serum bile acids and/or elevated transaminases. ${ }^{1}$ Although being accepted as a benign and temporary condition which resolves with the ceasing of the pregnancy, ICP is still of major interest to contemporary perinatal medicine, particularly due to the adverse outcomes as preterm delivery, non-reassuring fetal status, meconium staining of the amniotic fluid and stillbirth. ${ }^{2}$ The reported incidence of ICP varies between $0.1 \%$ and $15.6 \%$ in different geographical parts of the world. ${ }^{3,4}$ The reason for this difference is unknown. Recent studies about the etiology of ICP revealed multifactorial origin involving genetic and hormonal factors. It was also suggested that enviromental factors may have roles in the expres-

'Department of Perinatology, Zekai Tahir Burak Women's Health Care, Training and Research Hospital, Ankara, Turkey

Address of Correspondence: Cem Yaşar Sanhal

Department of Perinatology, Zekai Tahir

Burak Women's Health Care, Training and Research HospitalAnkara, Turkey cemsanhal@yahoo.com

Submitted for Publication:

11.01.2016

Accepted for Publication:

10.03.2016 sion of the disease. ${ }^{5}$ However, like the causes of the variations in the incidence, the certain etiology of the ICP is still unknown.

An abiotic or biotic factor that has influences on living organisms is defined as an enviromental factor. Temperature, amount of sunlight and $\mathrm{pH}$ of the water soil constitute most of the abiotic factors. ${ }^{6}$ Climatic and seasonal alterations have major effects on abiotic factors, and this issue has been taking on accumulating academic interest in order to enlighten the unknown associations between the gestational diseases and enviromental factors.

It was previously reported that ICP occured more commonly in colder months. ${ }^{7,8}$ This knowlege is relatively old and was determined in diminished population. Furthermore, climates are divided in to 5 groups or classes due to the aspects of the native vegetations namely: Tropical/megathermal; Dry; Temperate/mesothermal; Continental/microthermal; Polar and alpine. ${ }^{9}$ We perfomed our study in order to evaluate the presence of any seasonal variations in the frequency of ICP in a hospital of a city with continental climate.

\section{Material and Method}

The protocol of this prospective cohort study was approved by the ethics committee for human studies of Zekai Tahir Burak Women's Health Care, Training and Research Hospital and informed consent was taken from the participants. 
During the 24-month-period, from July 2013 to July 2015, women who were referred to Zekai Tahir Burak Women's Health, Education and Training Hospital for the perinatal care, were enrolled in the study. The hospital is a tertiary referral center in the capital of Turkey, Ankara. A total of 126 cases with ICP were compared with a cohort of 37614 pregnant women who delivered. The diagnosis ICP was performed on the basis of severe itching and the absence of dermal rash and any other hepatic disease with the co-existence of the elevated serum aminotransferase levels and/or serum bile acid concentration $(>10 \mu \mathrm{mol} / \mathrm{L})$. The accurate date of ICP diagnosis was determined due to the onset of symptoms and serum abnormalities.

Seasons were defined as winter (December, January, February), spring (March, April, May), summer (June, July, August), and fall (September, October, November). According to the Köppen climate classification, Ankara borders on a dry summer continental climate with a warm summer subtype and is near the borderline of a semi-arid climate. ${ }^{10}$ Ankara has cold, snowy winters and hot, dry summers. Rainfall occurs mostly during the spring and autumn.

SPSS statistical software for Windows, version 17.0 (SPSS, Inc., Chicago, Ill., USA) was used for statistical analysis. Normal distribution for continuous variables was assessed with the Kolmogorov - Smirnov test. Comparisons of parametric variables between groups with normal distributions were peformed by Student's t - test. The Mann - Whitney U test was used for comparisons of continuous variables that did not have normal distributions. A chi-square test or Fisher's exact test (for pairwise comparisons) was performed for nominal or ordinal variables between groups where appropriate. The seasonal impact in the frequency of ICP was assessed by chi - square test. The rate of monthly and seasonal number of newly diagnosed cases with ICP / monthly number of deliveries were calculated. In addition for each month and season, the observed and expected ICP rates were analysed and compared using chi - square statistics. Multivariate stepwise logistic regression with backward elimination was performed to investigate certain parameters on cumulative risk of ICH within groups. The model consisted of winter, spring, nulliparity, twin pregnancy and male fetus. A p-value $<0.05$ was considered significant.

\section{Results}

Table 1 demonstrates the demographic characteristics of the groups. The cases in the study group had a significantly lower number of parity, delivered earlier and also had lower neonatal birth weight. The rate of twin pregnancies were higher in patients with ICP.

Table 2 denotes the results of chi-squared tests of seasonal variation. Compared to other seasons, a significantly lower frequency of ICP for winter $(6 / 126(4.8 \%), p=0.001)$ and higher frequency of ICP for spring $(44 / 126(34.9 \%), p=0.034)$ were detected. The monthly number of cases and seasonal trend of ICP are depicted in Figure 1 and Figure 2, respectively.

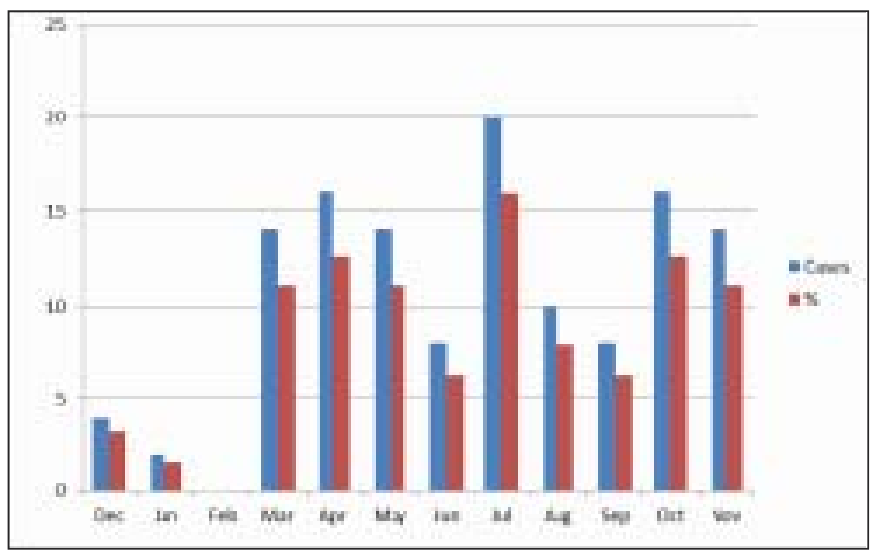

Figure 1: Monthly number of ICP cases

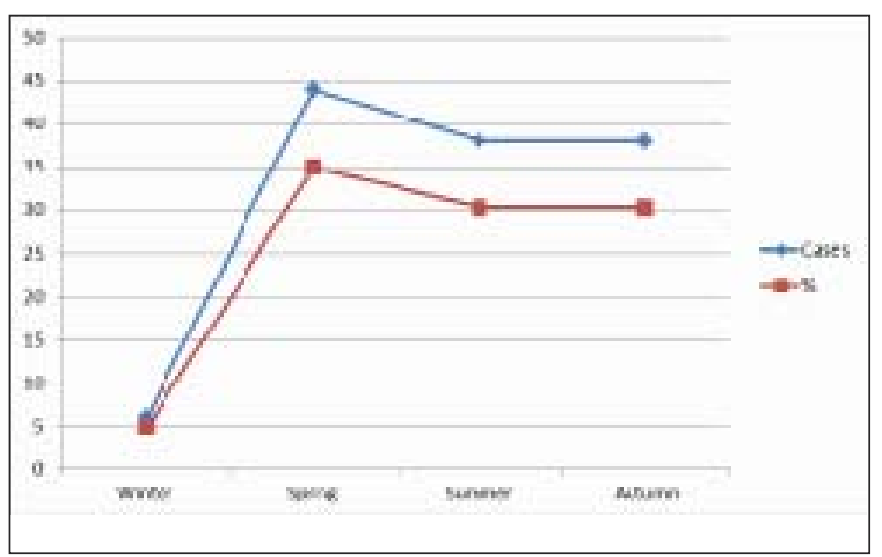

Figure 2: Seasonal trend of ICP

Table 1: Demographic characteristics of groups ${ }^{a}$

\begin{tabular}{lccc}
\hline & ICP $(\mathrm{n}=126)$ & Control $(\mathrm{n}=37614)$ & $\mathrm{p}$ value \\
\hline Age (years) & $28.3 \pm 5.6$ & $28.3 \pm 5.9$ & 0.960 \\
Parity (number) & $0(0-2)$ & $1(0-11)$ & $\mathbf{0 . 0 0 1}$ \\
Birth weight (grams) & $2877 \pm 502$ & $3110 \pm 637$ & $\mathbf{0 . 0 4}$ \\
Duration of gestation (weeks) & $36.4 \pm 1.9$ & $37.9 \pm 4.8$ & $\mathbf{0 . 0 1 3}$ \\
Twin pregnancies (number, \%) & $8(6.3)$ & $630(1.7)$ & $\mathbf{0 . 0 4}$ \\
Still birth (number, \%) & $0(0)$ & $272(0.7)$ & 1.0 \\
C/S (number, \%) & $76(60.3)$ & $19754(52.5)$ & 0.272 \\
\hline
\end{tabular}

ICP: Intrahepatic cholestasis of pregnancy, C/S: Cesarean section

a: Data are expressed as median (min-max), mean \pm standard deviation and number, $\%$ where appropriate. b: $p<0.05$ indicates significant difference 
The findings of logistic regression models are shown in Table 3. A 2.1 and 3.8-fold higher risks were found for the nulliparity and twin pregnancy, respectively. The winter made a significant (10-fold) decrease in the frequency of ICP. The significance of the effect of the spring on ICP did not persist after the adjustment.

\section{Discussion}

In this study, we evaluated the relation between the seasons and the ICP frequency of our hospital. We found that the number of new cases with ICP was significantly lower in winter and higher in spring. Moreover, the effect of the winter (but not for spring) on this result remained significant (an approximately 10-fold lower risk) after adjusting for potential confounders in logistic regression model. Additionally, nullipartiy and twin pregnancy were associated with higher risks for ICP.

Earlier studies from Scandinavia and Chile had shown evidence of seasonality in ICP, especially higher risks for colder months. ${ }^{7,8}$ These results seem contradictory to our findings. However, the data were established in lands that belong to different groups in Köppen climate classification ${ }^{10}$ regarding Ankara, and the reason of the conflict may be due to the alterations in the winter characteristics of different climates. From this point of view, our study reveals the priliminary data of a pregnancy population living in a continental climate.

Despite the extensive research, much of the pathogenesis of ICP is still unknown. The former data pointed a genetic tendency in the etiology. A 5 to 12-fold increased risk of ICP development in the mothers, parous sisters and daughters of the index patients denoted evidence about the issue. ${ }^{11}$ The gene deficiency of ATP-binding cassette subfamily B member 4 (ABCB4) membrane transporter, which plays role in the bile acid export metabolism, was also reported to be in association with cholestatic liver diseases. ${ }^{12}$ Moreover, heterozygosity of the common $\mathrm{ABCB} 11$ mutations and the mutations of the other phospholipid transporter encoding gene, ATP8B1, were both shown to be involved in a number of patients with the

Table 2: Results of chi-squared tests of seasonal variation performed on monthly and seasonal frequencies for cases of ICP during the study period

\begin{tabular}{|c|c|c|c|c|c|}
\hline \multirow{2}{*}{ - } & \multicolumn{2}{|l|}{$\operatorname{ICP}(\mathrm{n}: 126)$} & \multicolumn{2}{|l|}{ Control (n:37614) } & \multirow[t]{2}{*}{$\mathrm{p}^{\mathrm{a}}$} \\
\hline & Observed & Expected & Observed & Expected & \\
\hline Winter & $6(4.8 \%)$ & 28.4 & $8450(22.5 \%)$ & 8465 & 0.001 \\
\hline December & $4(3.2 \%)$ & 9.8 & $2938(7.8 \%)$ & 2932 & 0.237 \\
\hline January & $2(1.6 \%)$ & 10 & 2982 (7.9\%) & 2974 & 0.063 \\
\hline February & $0(0 \%)$ & 8.6 & $2570(6.8 \%)$ & 2562 & 0.021 \\
\hline Spring & $44(34.9 \%)$ & 29.8 & $8860(23.6 \%)$ & 8875 & 0.034 \\
\hline March & $14(11.1 \%)$ & 9.8 & $2924(7.8 \%)$ & 2928 & \\
\hline \multicolumn{6}{|l|}{0.324} \\
\hline April & $16(12.7 \%)$ & 9.6 & $2858(7.6 \%)$ & 2864 & 0.146 \\
\hline May & $14(11.1 \%)$ & 10.4 & $3078(8.2 \%)$ & 3081 & 0.398 \\
\hline Summer & $38(30.2 \%)$ & 34.2 & $10176(27.1 \%)$ & 10180 & 0.580 \\
\hline June & $8(6.3 \%)$ & 10.6 & $3172(8.4 \%)$ & 3170 & 0.552 \\
\hline July & $20(15.9 \%)$ & 12.2 & 3664 (9.7\%) & 3672 & 0.102 \\
\hline August & $10(7.9 \%)$ & 11.2 & $3340(8.9 \%)$ & 3339 & 0.793 \\
\hline Autumn & $38(30.2 \%)$ & 30 & 8952 (23.8\%) & 8960 & 0.237 \\
\hline September & $8(6.3 \%)$ & 10.2 & $3060(8.1 \%)$ & 3058 & 0.605 \\
\hline October & $16(12.7 \%)$ & 20.4 & $3028(8.1 \%)$ & 3033 & 0.176 \\
\hline November & $14(11.1 \%)$ & 9.6 & $2864(7.6 \%)$ & 2868 & 0.334 \\
\hline
\end{tabular}

ICP: Intrahepatic cholestasis of pregnancy, a: $p<0.05$ indicates significant difference

Table 3: Impact of factors on intrahepatic cholestasis of pregnacy

\begin{tabular}{lcccc}
\hline Characteristics & Crude odds ratio & Confidence Interval & Adjusted Odds ratio & Confidence Interval \\
\hline Winter & 0.172 & $0.054-0.547$ & 0.171 & $0.054-0.546$ \\
Spring & 1.741 & $1.036-2.926$ & 1.227 & $0.730-2.63$ \\
Nulliparity & 2.264 & $1.370-3.742$ & 2.067 & $1.249-3.421$ \\
Twin pregnancy & 3.913 & $1.410-10.857$ & 3.751 & $1.346-10.451$ \\
Male fetus & 1.518 & $0.915-2.516$ & 1.474 & $0.887-2.443$ \\
\hline
\end{tabular}

Bold typeface indicates significance 
progressive intrahepatic cholestasis, because of the decrease in the folding ability of the bile salt export pump protein. ${ }^{13,14}$

Although the dysregulations from seasonal patterns take part in the occurence of some cardiovascular, autoimmune and psychiatric illnesses. ${ }^{15-17}$ the effects of seasonal variations on human tissue functions are not broadly studied. However in 2015, Dopico et al. showed the different seasonal expression profiles of more than 4000 protein-coding mRNAs in white blood cells and adipose tissue, and also the international alterations of the cellular composition of the blood that varies by season, which could explain the gene expression periodicity. ${ }^{18}$ In our opinion, the findings of this interesting study are critical for the enlightening of the diseases like ICP, which may be influenced by the genetic mutations and also present with seasonality. In other words, seasonal variations may generate the transitory decompensation of the heterozygous circumstance for genes encoding hepatobiliary transport elements which deteriorate during the course of gestation, and resulting in ICP.

Incomplete illumination in the pathogenesis of ICP enforced the researchers also to investigate the immunologic and hormonal base of the disorder. As demonstrated in our study, the increased risk of twin pregnancies, ${ }^{19}$ and the usual third trimester onset when the serum levels of estrogen reach their peak, ${ }^{20}$ may connote the association between hormones (mainly estrogens and progesterone) and ICP. It is known that the immunologic balance of the normal pregnancy is ensured by the interaction of CD4 $(+)$ and CD8 $(+)$ T cells, in which the CD8 (+) T cell activity is more prominent. ${ }^{21}$ It was also ascertained that the high levels of estrogen decreased the activity of CD8 (+) T cells that might lead to ICP. ${ }^{22}$ A population based trial exploring the seasonal variation of estradiol levels reported the significant differences in the total and free estradiol monthly means; highest level in June and nadir in November. ${ }^{23}$ Although being conducted in non-pregnant women and in a city (Tromso, Norway) with different climate properties regarding Ankara, this study and the estrogen effect on $\mathrm{T}$ cells revealed the necessity of new trials exploring the seasonal change in the serum levels of sex hormones in pregnant women and the potential immunologic - tissue effects of these changes in ICP.

Furthermore, seasonal variations have some confirmed effects on maternal levels of non-hormonal compounds. A remarkable higher rate of vitamin D deficiency in pregnant women during the winter season was reported in a study performed in Ankara. ${ }^{24}$ This finding is important because Vitamin $\mathrm{D}$ and its receptor control important steps in bile acid detoxification. ${ }^{25}$ On the other hand, it also reveals a contradiction about one of the most significant result of our study denoting the potential protective effect of winter against the occurence of ICP.

Afterall, there are some limitations of our study. First, the major finding indicating the significantly lower number of ICP cases in winter, can not be generalized. The reason of this en- tity is the distinct climate and winter characteristics in divergent geographic parts of the world. Second, the investigation of the interactions between seasonal variations and the potential factors for ICP as genetic mutations, sex hormones and non-hormonal substances, which were not examined in this study, may reveal more valuable data to unveil ICP etiology. And finally, the trials with longer durations and higher number of participants may declare more reliable findings about the main objective of this study.

The etiology of ICP is complex with genetic, endocrine, and environmental factors having major roles. In this study, we showed the seasonal variations in the number of new diagnosed cases with ICP. Further studies in different population and climates with the evaluation of all confounder factors in ICP etiology may reveal more informative data about the contention.

\section{References}

1. Lammert F, Marschall HU, Glantz A, Matern S. Intrahepatic cholestasis of pregnancy: molecular pathogenesis, diagnosis and management. J Hepatol 2000; 33(6):1012-21.

2. Jin J, Pan SL, Huang LP, Yu YH, Zhong M, Zhang GW. Risk factors for adverse fetal outcomes among women with early- versus late-onset intrahepatic cholestasis of pregnancy. Int J Gynaecol Obstet 2015;128(3):236-40.

3. Pan C, Perumalswami PV. Pregnancy-related liver diseases. Clin Liver Dis 2011;15(1):199-208.

4. Bacq Y. Intrahepatic cholestasis of pregnancy. Clin Liver Dis 1999;3:1.

5. Than NN, Neuberger J. Liver abnormalities in pregnancy. Best Pract Res Clin Gastroenterol 2013;27(4):565-75.

6. Gilpin A. Dictionary of Environment and Sustainable Development. John Wiley and Sons 247;1996.

7. Berg B, Helm G, Petersohn L, Tryding N. Cholestasis of pregnancy. Clinical and laboratory studies. Acta Obstet Gynecol Scand 1986;65(2):107-13.

8. Reyes H, Gonzalez MC, Ribalta J, et al. Prevalence of intrahepatic cholestasis of pregnancy in Chile. Ann Intern Med 1978;88(4):487-93.

9. McKnight TL, Hess D. Climate Zones and Types. Physical Geography: A Landscape Appreciation. Upper Saddle River, NJ: Prentice Hall;2000.

10. Kottek M, Grieser J, Beck C, Rudolf B, Rubel F. World map of the Köppen-Geiger climate classification updated. Meteorol Z 2006;15:259-63.

11. Turunen K, Helander K, Mattila KJ, Sumanen M. Intrahepatic cholestasis of pregnancy is common among patients' first-degree relatives. Acta Obstet Gynecol Scand 2013;92(9):1108-10.

12. Oude Elferink RP, Paulusma CC, Groen AK. Hepatocana- 
licular transport defects: pathophysiologic mechanisms of rare diseases. Gastroenterology 2006;130(3):908-25.

13. Dixon PH, van Mil SW, Chambers J, et al. Contribution of variant alleles of ABCB11 to susceptibility to intrahepatic cholestasis of pregnancy. Gut 2009;58(4):537-44.

14. Srivastava A. Progressive familial intrahepatic cholestasis. J Clin Exp Hepatol 2014;4(1):25-36.

15. Hung MJ, Hsu KH, Chang NC, Hung MY. Increased Numbers of Coronary Events in Winter and Spring Due to Coronary Artery Spasm: Effect of Age, Sex, Smoking, and Inflammation. J Am Coll Cardiol 2015;65(18):2047-8.

16. Moltchanova EV, Schreier N, Lammi N, Karvonen M. Seasonal variation of diagnosis of Type 1 diabetes mellitus in children worldwide. Diabet Med 2009;26(7):673-8.

17. Suhail K, Cochrane R. Seasonal variations in hospital admissions for affective disorders by gender and ethnicity. Soc Psychiatry Psychiatr Epidemiol 1998;33(5):211-7.

18. Dopico XC, Evangelou M, Ferreira RC, et al. Widespread seasonal gene expression reveals annual differences in human immunity and physiology. Nat Commun 2015; 6:7000.

19. Baliutaviciene D, Zubruviene N, Zalinkevicius R. Pregnancy outcome in cases of intrahepatic cholestasis of pregnancy. Int J Gynaecol Obstet 2011;112(3):250-1.

20. Reyes H. Review: intrahepatic cholestasis. A puzzling disorder of pregnancy. J Gastroenterol Hepatol 1997;12(3): 211-6.

21. Mincheva-Nilsson L, Hammarström S, Hammarström ML. Human decidual leukocytes from early pregnancy contain high numbers of gamma delta + cells and show selective down-regulation of alloreactivity. J Immunol 1992; 149(6):2203-11.

22. Yayi H, Danqing W, Shuyun L, Jicheng L. Immunologic abnormality of intrahepatic cholestasis of pregnancy. Am J Reprod Immunol 2010;63(4):267-73.

23. Bjornerem A, Straume B, Oian P, Berntsen GK. Seasonal variation of estradiol, follicle stimulating hormone, and dehydroepiandrosterone sulfate in women and men. J Clin Endocrinol Metab 2006;91(10):3798-802.

24. Ustuner I, Keskin HL, Tas EE, Neselioglu S, Sengul O, Avsar AF. Maternal serum 25(OH)D levels in the third trimester of pregnancy during the winter season. J Matern Fetal Neonatal Med 2011;24(12):1421-6.

25. Zollner G, Trauner M. Nuclear receptors as therapeutic targets in cholestatic liver diseases. Brit $\mathrm{J}$ Pharmacol 2009;156(1):7-27. 